\title{
INFORMED SPECULATION ON THE CAUSE OF SLEEPING SICKNESS 1898-1903
}

THE incrimination of the trypanosome as the cause of sleeping sickness and the discovery of the transmission of the parasite by the tsetse fly was the result of studies carried out in Uganda by Castellani, Bruce, Nabarro and others. ${ }^{1}$ While there is no question of the importance of their elucidation of the relation between the disease, the parasite and the vector, by clinical, laboratory, and field work, the long controversy over the attribution of credit between these workers that continued for so many years $^{1}$ has tended to obscure the interesting fact that informed speculation by others, with very varying experiences of the disease, had pointed to all the aspects of the situation which were later shown to be important, the parasite, the vector and aspects of the ecologic situation.

The early history of sleeping sickness has often been recorded and Hirsch ${ }^{2}$ summarized existing knowledge and theories of the 1880s and this was brought up to date in a clinical lecture delivered by Patrick Manson at Charing Cross Hospital in 1898. ${ }^{3}$ He had seen in consultation the two patients of Stephen Mackenzie's some years previously and it was in the blood of these that the filaria, Dipetalonema perstans, was first identified. Manson had two patients of his own to dilate on in the clinical lecture and was much influenced by the little African boy who had been sent from the Congo to a school in Wales where after a long interval he had developed sleeping sickness. The boy had not been unhappy in this Welsh school, no other children had been affected, the boy had not been consuming manioc, or raw fish, or palm wine and certainly had not been indulging in excessive venery. The Welsh sun was hardly strong enough to penetrate the negro cranium and injure the brain. While existing evidence in Africa pointed strongly to sleeping sickness being an infective disease no cases had developed in the West Indies from contact with imported slaves who had developed the disease. The most careful bacteriological studies of blood and of the enlarged lymph glands in the patients seen in England had been entirely negative but in the blood of all cases Dipetalonema perstans had been found. The cause of the disease in the boy seemed to be some infectious agent only contracted in his Congo homeland which, after a long incubation period, caused the disease.

Manson thus indicated the conditions that any aetiologic suggestions must explain. These were: causation by a living agent, one capable of remaining latent in the body for long periods, only acquired in certain localities, not capable of being introduced into some virgin areas, one not spreading directly from person to person but dependent, directly or indirectly on the flora or fauna in certain localities. Everything in the epidemiology of sleeping sickness pointed, in Manson's view, to its being due to some living agent that had, at some stage or other in its existence, to pass through the body of a lower animal, or possibly a plant found only in certain equatorial areas of Africa.

Of the possible candidates for the dubious honour Manson considered that a case could be made for Dipetalonema perstans though he recognized some difficulties. Firstly it has been found in Guyana whence sleeping sickness had never been recorded and this would be a fatal objection were it not that Dr. Ozzard ${ }^{4}$ considered that such 


\section{News, Notes and Queries}

was the medical backwardness of the area that the disease might well exist unrecorded. Moreover, perstans was found in persons who showed no signs whatsoever of sleeping sickness. But Manson seized on a special significance of the enlarged cervical lymph nodes so well recognized as being present in the early stages of sleeping sickness. This suggested to him an analogy with Bancroftian filariasis in which the parasite seemed relatively harmless to many infested but could on occasion, by then unknown mechanisms, produce such striking lesions as elephantiasis or chyluria. Perstans might act similarly, on the one hand being in those most affected a harmless commensal, but on the other hand possibly producing the enlarged lymph glands and somehow producing damage in the brains of other victims. The vector of perstans was not known, it was presumably some mosquito, and concordance of parasite and vector in certain areas only could explain the geographic localizations of sleeping sickness.

Manson thus in $\mathbf{1 8 9 8}$ had clearly seen all the basic essentials in the sleeping sickness situation though as it happened he did not have the right parasite or the right vector. He had no reason at the time to suspect that trypanosomes caused any human disease and though familiar since the publication of the work of Bruce on animal trypanosomiasis in Zululand, and thus of the tsetse fly as an animal disease vector, yet the unanimous opinion at the time that the bite of the tsetse was harmless to man must have prevented him even considering the tsetse fly as a potential vector. This undoubtedly militated against the discovery of the trypanosome and tsetse fly relationship for some years and explains why there was delay. Considering Manson's views and the influence he exerted in tropical medicine it is surprising that the parasite and vector were not immediately discovered. At the outset of the sleeping sickness epidemic the medical men in Uganda had found perstans in the blood of sleeping sickness patients and it was a parasite they had never seen before-thus giving Manson's hypothesis a spurious support.

But, seemingly unknown to Manson it so happened that Prof. J. Brault of the Medical School in Algiers had, almost simultaneously but for quite different reasons, suggested both the right parasite and the right vector. ${ }^{5}$ An occasional case of sleeping sickness was seen in Algiers but more were seen in Timbuktu whence in 1897 Regis and Gaide ${ }^{6}$ had reported on the brain lesions seen in a single case and described them as those of a diffuse non-suppurative meningo-encephalitis. Earlier Cagigal and Lepierre $^{7}$ had isolated a bacillus from a patient with sleeping sickness which they claimed would on injection into animals produce a disease like sleeping sickness. Brault obtained this bacillus and with Dr. Lapin ${ }^{8}$ was unable to reproduce these results, the lesions produced apparently being suppurative in type. Meanwhile Brault had been studying trypanosome infections in animals with his colleague, Dr. Rouget. Trypanosomes were a subject of much interest in Algiers in 1896-98 for Nepveu had found in the blood of a patient in Algiers an organism that seemed to be a trypanosome. Considerable obscurity surrounds this episode. It would seem that the patient was not ostensibly suffering from sleeping sickness and the ultimate fate of the patient is unknown. Nepveu's drawings and descriptions were condemned as quite inadequate to support his identification when they were studied by Laveran and Mesnil, ${ }^{10}$ the greatest authorities on trypanosomes of the time, and Nepveu's claims have been generally, and probably rightly, dismissed. They may have been accepted locally. 


\section{News, Notes and Queries}

However, Brault ${ }^{11}$ had seen large numbers of animals dying following injections of a trypanosome and he had been struck by the resemblance of the disease in larger animals, dogs and rabbits, to the signs and symptoms seen in human sleeping sickness-especially 'somnolence, apathy, marked wasting, irregular fever, insensibility, paralysis of limbs and sphincters.' Also certain other features he had noted in human patients, early lymphadenopathy and local oedemas, were seen in these animals. It had therefore seemed to Brault that trypanosome infection might be the cause of sleeping sickness.

His first statement on this is given in a footnote to a paper ${ }^{5}$ 'Contribution à la géographie médicale des maladies africaines' published in Janus of 1898 . He discussed briefly in his paper the distribution of sleeping sickness and filariasis noting Manson's speculations. The footnote reads 'Actuellement la parasitologie et la bactériologie se disputent la pathogénie de nélevane; en raison de la march si spéciale de la maladie et de sa localisation géographique; je pencherais volontiers pour un protozoire sanguicole dans le genre du trypanosome qui est probablement l'auteur des méfaits attribués à la mouche tsé-tsé.'

He repeated these ideas in two books completed in Paris in 1899,11,12 'en raison de l'incubation si longue, en raison de la marche si lente et si spéciale de la maladie je croirais volontiers à un parasite sanguicole dans le genre des trypanosomes rencontrés chez les animaux' and went on to give the reasons outlined previously.

Brault ${ }^{13}$ tried in vain to get support to investigate cases of sleeping sickness, even asking the Portuguese authorities to send to France two sleeping sickness patients from Angola for him to study and search for trypanosomes. Alas all his hopes foundered 'en raison de considerations surtout budgetaires.' There can be little doubt that these financial reasons deprived Brault of the credit of the discovery of trypanosomes in sleeping sickness patients because had these been examined to find trypanosomes by Brault, who was familiar with animal trypanosomes, there is no doubt, as later experience showed, they would have been discovered.

But at the end of 1898 any informed person who had noted these communications of Manson and Brault might have gone ahead rapidly to incriminate both trypanosome and tsetse fly. In retrospect it is rather surprising that more progress was not made till 1903. But before the news of the discovery of the trypanosome in sleeping sickness cases in Uganda was known in London, the British Medical Journal of 30 March 1903 published an article by Dr. A. Maxwell Adams. ${ }^{14}$ He had in Gambia been called in consultation by Dr. Forde over the patient in whose blood were mysterious 'worms' subsequently identified by Dr. J. L. Dutton as trypanosomes and named T. gambiense. Dr. Maxwell Adams had brooded over the case and wondered if the parasite might be spread from rat to man by the bite of some insect or mosquito. He believed that sleeping sickness was commoner in Gambia than had been recognized and contrary to current opinion considered that the disease did affect Europeans. He had noted the curious puffy face in Dr. Forde's patient, a feature he had noted also in sleeping sickness. He asked four questions designed to promote future research and the last was: 'Has the trypanosoma anything to do with sleeping sickness?' Contrasting trypanosome fever with sleeping sickness he remarked 'though the symptoms of the two diseases are different might they not be different stages of the same process- 
in the first stage the parasite circulating freely in the blood, in the second stage accumulating in the brain and causing somnolency through local anaemia.'

Unknown to Adams his ideas were being confirmed in Uganda at the time he wrote, and how much these ideas were 'in the air' at the time is shown by the actions of Dr. C. J. Baker ${ }^{15}$ who in 1903 was in charge of the Native Dispensary at Entebbe, Uganda. Baker had seen trypanosoma gambiense at a demonstration of Manson's the previous November. Several days before David Bruce and the Royal Society's sleeping sickness commission arrived at Entebbe, Baker found trypanosomes in the blood of a policeman who had never been outside Uganda. The identification was confirmed by Dr. Moffat and by Castellani who then told Baker and Moffat that he had previously found trypanosomes in the blood and C.S.F. of sleeping sickness patients. Castellani examined the C.S.F. of Baker's patient with negative results. Baker immediately suspected the biting flies and started a collection which he handed Bruce on the latter's arrival, and one of these flies was a Glossina Palpalis.

The controversies that followed the incrimination of the trypanosome as the cause of sleeping sickness in Uganda in 1902-03 over the attribution of credit, in particular the controversy as to who first realized the importance of the trypanosomes being found in the C.S.F. can now be seen to be largely irrelevant and founded, as has been shown elsewhere ${ }^{16}$ on personal jealousies and departmental rivalries which had little to do with the sleeping sickness investigations. While neither Baker nor Moffat saw the relevance of their case of trypanosome fever immediately, the arrival of Maxwell Adams' paper would have later opened their eyes to the possibility that trypanosomes accumulating in the brain caused sleeping sickness. Castellani would have been bound to come to the same idea. As far as David Bruce is concerned-in his first 24 hours in Uganda he was shown a case of trypanosome fever and saw slides of the parasite, was handed a collection of biting flies amongst which he recognized a tsetse fly and heard of the discovery of trypanosomes in the C.S.F. of five cases of sleeping sickness. Rarely can the investigator of the cause of an obscure disease be handed quite so much immediately relevant information in so short a time at the outset of his investigations and one did not have to be a microbiologist of genius, or even a Fellow of the Royal Society to realize that here were immediate leads to be followed up. This is just what Bruce and Nabarro did so excellently.

But so rapidly did confirmation of Castellani's discovery come from other areas of Africa that it is evident that in the climate of ideas in 1903 the trypanosome and tsetse fly relationship in causing sleeping sickness was immediately acceptable to all informed opinion, save oddly enough to Patrick Manson himself. His disciples took it up avidly and Sambon ${ }^{4}$ saw instantly how the glossina palpalis could be the soughtfor vector over much of western Africa before the results of the Bruce-Nabarro investigations were to hand. It seems impossible that the views of Brault were not known to Bruce, and indeed to others in Uganda, for the British Foreign Office sent to Uganda in 1902 a complete collection of what had been published on sleeping sickness. It is Brault's misfortune that his views were not more widely stressed and known and that his own investigations foundered on "considerations surtout budgetaires' thus depriving him of the distinction of having confirmed his hypothesis.

Nonetheless the field and laboratory investigations completed and blocked in the 


\section{News, Notes and Queries}

theories reached by Manson, Brault and Maxwell-Adams and this episode is thus of some interest to students of the history of ideas.

\section{REFERENCES}

1. Scotr, H. H., A History of Tropical Medicine, Baltimore, Williams and Wilkins, 1939.

2. Hirsch, A., Handbook of Geographical and Historical Pathology, London, New Sydenham Society, 1886.

3. MAnson, P., 'A clinical lecture on the sleeping sickness', Brit. med. J., 1898, ii, 1672-77.

4. SAMBON, L., 'Sleeping sickness in the light of recent knowledge', J. trop. Med., 1903, 5, 205. Quotes Dr. Ozzard.

5. Brault, J., 'Contribution à la géographie médicale des maladies africaines', Janus $1898,3,36-42$.

6. ReGrs, E., and GAIDE, N., 'Rapports entre la maladie du sommeil et le myxoedème', Presse Medicale, 1898, 2, 193.

7. CaGigal, A., and LePierre, C., 'La maladie du sommeil et son bacillus', $C$. r. Séanc. Soc. Biol., 1898, 10, 89-92.

8. Brault, J., and Lapin, J., 'Note sur l'étiologie et la pathogénie de la maladie du sommeil', Arch. parasitol, 1898, 1, 369-78.

9. NEPVEu, G., 'Sur un trypanosome dans le sang de l'homme', C. r. Séanc. Soc. Biol., $1898,10,1172-74$.

10. LaVeran, A., Mesnil, F., Trypanosomes and Trypanosomiasis, trans. Nabarro, D., London, Bailliere, Tindall and Cox, 1907.

11. Brault, J., Hygiène et Prophylaxie des Maladies des Pays Chauds de l'Afrique Française, Paris, Baillière, 1900.

12. Brault, J., Traité Pratique des Maladies des Pays Chauds et Tropicaux, Paris, Baillière, 1900.

13. Brault, J., 'Note sur l'historique de l'étiologie de la maladie du sommeil', Janus, $1907,12,7-9$.

14. Maxwell-Adams, A., 'Trypanosomiasis and its cause', Brit. med. J., 1903, i, 721-22.

15. BAKER, C. J., 'Three cases of trypanosoma in man in Entebbe, Uganda', Brit. med. J., $1903, \mathrm{i}, 1254-56$.

16. Davies, J. N. P., 'The cause of sleeping sickness: Entebbe 1902-03', E. Afr. med. J., 1962, 39, 81-99.

J. N. P. DAVIES

\section{SEMMELWEIS ANNIVERSARY WEEK \\ BUDAPEST, 10-16 NOVEMBER, 1968}

The 150th anniversary of the birth of the great Hungarian obstetrician Ignaz Philipp Semmelweis is to be celebrated with a special anniversary week, organized with the participation of the Hungarian Ministry of Health, the Hungarian Academy of Sciences, the Union of Medical Workers, and the Medical University of Budapest. A very full programme has been planned, and there will be sessions on both modern clinical subjects and historical topics.

Participants in the conference will have opportunities for sightseeing in Budapest, and excursions will be organized to local places of interest.

All correspondence and enquiries concerning the conference should be addressed to the Secretariat: Motesz, Budapest I, Apród u. 1/3, Hungary. 